\title{
Successful percutaneous closure of a tortuous coronary artery to pulmonary artery fistula using the anchor technique: a different approach
}

\author{
Isa Oner Yuksel, Erkan Koklu, Goksel Cagirci, Selcuk Kucukseymen, Gorkem Kus, Sakir Arslan \\ Antalya Training and Research Hospital, Antalya, Turkey
}

Postep Kardiol Inter 2015; 11, 4 (42): 344-346 DOI: $10.5114 /$ pwki.2015.55610

\begin{abstract}
Introduction
Coronary artery fistula (CAF) is described as an anomalous connection between a coronary artery and a major vessel or cardiac chamber. It can result in myocardial ischemia, heart failure, pulmonary hypertension, bacterial endocarditis, and rupture of aneurysmal vessels [1]. The majority of these fistulae originate from the left anterior descending artery or from the right coronary artery [2]. Symptomatic coronary artery fistulae are usually treated with percutaneous intervention or surgical correction [3]. We report herein a case of successfully performed percutaneous coil embolization of a tortuous coronary artery fistula using the anchor technique.
\end{abstract}

\section{Case report}

A 60-year-old man was examined for retrosternal pain radiating to the left upper limb. The electrocardiogram showed normal sinus rhythm. The transthoracic echocardiogram demonstrated a normal left ventricular size and mild concentric left ventricular hypertrophy with abnormal regional wall motion in the inferior segment. A myocardial perfusion scintigraphy test was performed, revealing mild reversible inferior ischemia. Six months before, this patient had come with the same complaints, and percutaneous coronary intervention was performed on the right coronary artery (RCA) due to a critical lesion; also coronary fistula originating from the proximal portion of the circumflex artery to the pulmonary artery (Figure $1 \mathrm{~A}$ ) was observed, but it was not planned to intervene.

This time, diagnostic coronary angiography was performed again; it revealed no significant atherosclerotic stenosis and a patent stent in the RCA, and the fistula was seen again. The fistula was relatively large, with an approximate diameter of $2.8 \mathrm{~mm}$.
We inferred that the angina and inferior ischemia revealed by myocardial perfusion scintigraphy occurred due to the fistula and coronary artery steal. Therefore, we planned to perform percutaneous coil embolization of the fistula.

A 7-Fr EBU 4.5 coronary guiding catheter (Launcher, Medtronic, Minneapolis, MN, USA) was inserted into the right femoral artery and engaged in the left coronary artery. During the procedure, $7000 \mathrm{U}$ of heparin (at a dose of $100 \mathrm{U} / \mathrm{kg}$ ) were administered intravenously. We initially planned to introduce the guidewire distally to the fistula and scroll a microcatheter through a guidewire to perform coil embolization. A 0.014-inch guidewire (Regalia XS, Asahi Intecc, Aichi, Japan) was inserted into the fistula. However, due to extreme tortuosity, a 2.5-Fr Cantata TM-18 microcatheter (Cook Medical, Bjaeverskov, Denmark) was not successfully advanced over the guidewire to the distal end of the fistula. At this stage, a 0.014 guidewire was advanced to the thin lateral branch vessel at the proximal part and was anchored to provide support (Figure $1 \mathrm{~B}$ ). The microcatheter was advanced into the side branch successfully via a guidewire which was anchored. After this stage, the coil embolization system was placed successfully through the microcatheter. The coil was placed in the body of the fistula by opening the remainder of it. This experiment was carried out to reduce the possibility of coronary embolism during the return of the coil. The coil was released after complete removal from the microcatheter and found to be stable under fluoroscopy (Figure 2 A). After coil embolization, the final coronary angiogram did not show flow through the shunt between the coronary artery and the pulmonary artery (Figure $2 \mathrm{~B}$ ).

The patient's post-procedure course was uneventful, and no major complications, such as coil migration or dis-

\section{Corresponding author:}

Dr Selcuk Kucukseymen, Antalya Training and Research Hospital, Varlık Mahallesi Kazım Karabekir Caddesi Soğuksu, 07100 Antalya, Turkey, fax: +90 5074315691, e-mail: skucukseymen@gmail.com

Received: 15.08.2014, accepted: 26.08.2015. 

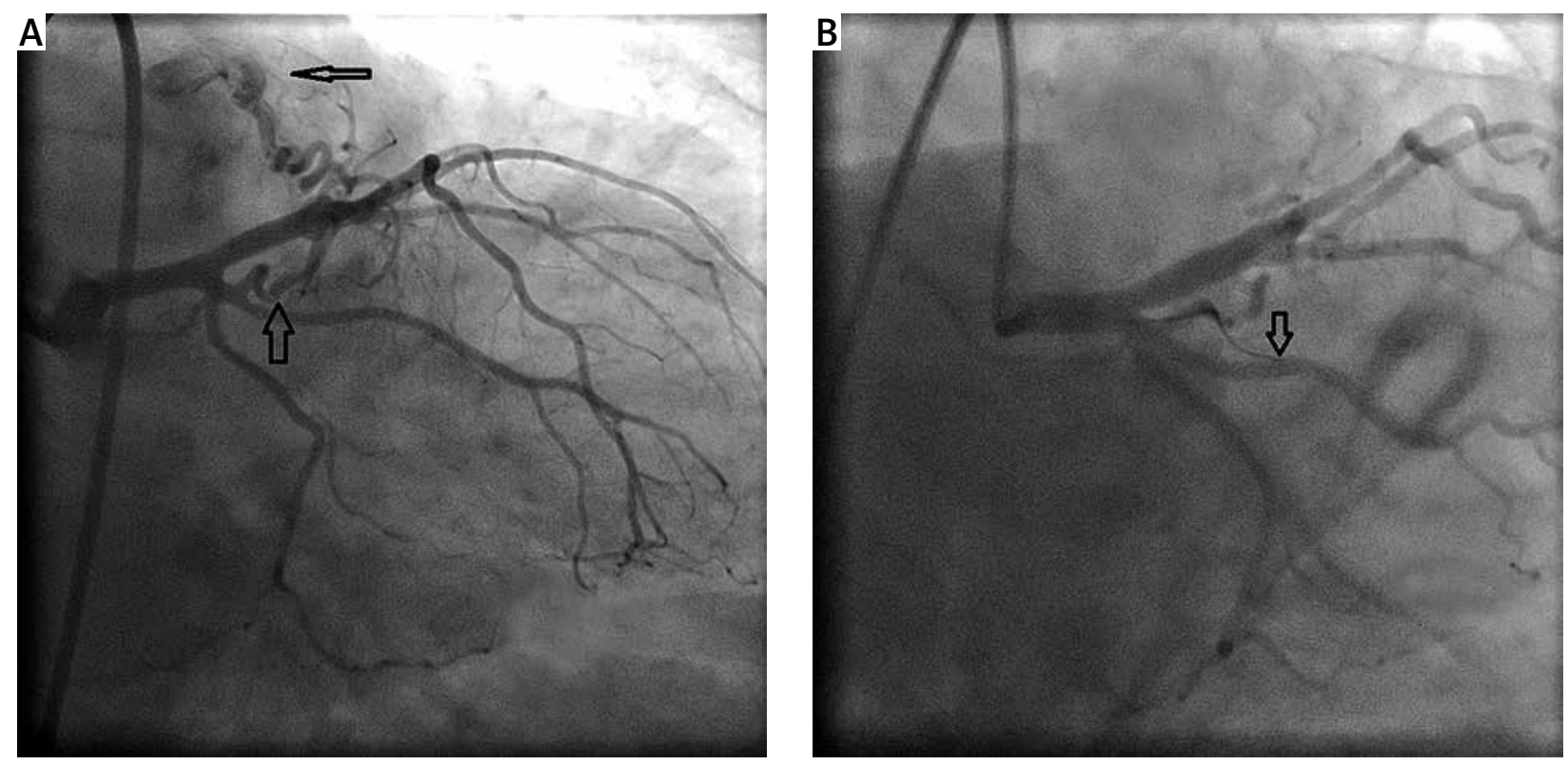

Figure 1. A - The fistula connecting the tortuous circumflex coronary artery to the pulmonary artery (thin arrow) and the fistula arising from the obtuse marginal branch (thick arrow) of the circumflex artery. B - Anchoring of the side branch
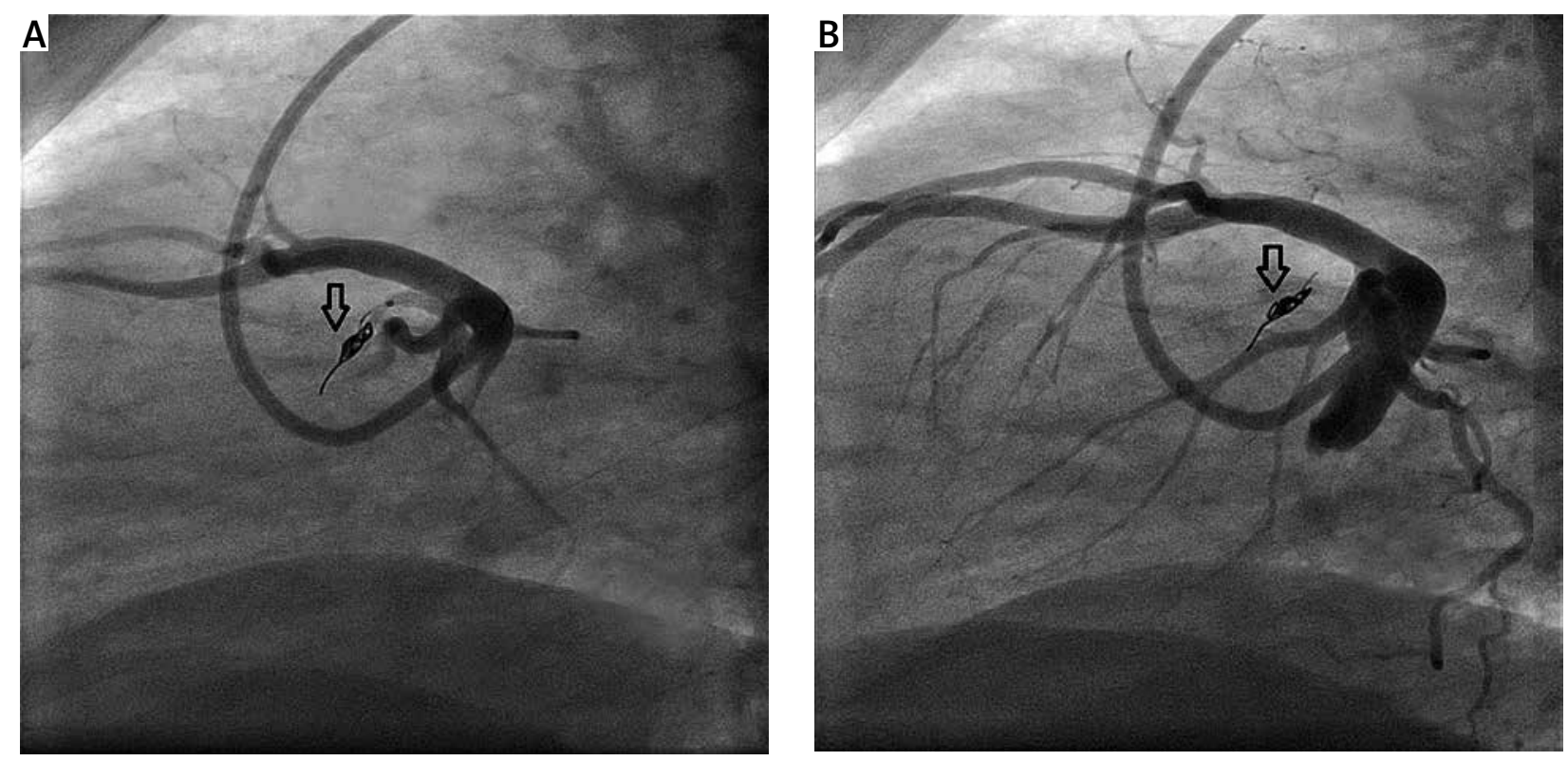

Figure 2. A - Coil embolization. B - Post-coil embolization: the coil closing the fistula; there is no flow through the shunt between the coronary artery and the pulmonary artery (arrow)

tal coronary embolization, were observed. The patient's symptoms were resolved. Two days after the procedure, he was discharged without any complications. The patient was asymptomatic during a 3-month follow-up.

\section{Discussion}

Coronary artery fistula is an uncommon presentation of congenital heart disease. The prevalence of coronary artery fistulae is relatively low and they are incidentally observed in $0.05 \%$ to $0.2 \%$ of coronary angiograms $[3,4]$.
Similarly, the incidence of coronary to pulmonary artery fistulae is reported to be $0.1 \%$ [5]. Due to the low prevalence of coronary artery fistulae, the optimal treatment strategy remains unclear, and there are no established therapeutic guidelines available.

The etiology of CAF may be congenital, traumatic or iatrogenic such as after coronary intervention or valve surgery. A connection between a coronary artery and a cardiac chamber is less frequent. The most prevalent recipient chamber is the right ventricle (45\%), followed 
by the right atrium (25\%), and the pulmonary artery (20\%) [6]. However, CAF between a coronary artery and the left chamber is rarely observed.

Coronary to pulmonary artery fistulae are occasionally and incidentally found in the adult coronary angiography suite. The potential complications of it include pulmonary hypertension and congestive heart failure if a large left-to-right shunt exists, bacterial endocarditis, rupture or thrombosis of the fistula or of an associated arterial aneurysm, and myocardial ischemia distal to the fistula due to a myocardial steal [1]. Clinical symptoms of coronary ischemia, such as exertional angina or dyspnea, are the primary indications of closure of the fistula [7].

The treatment options for CAF include conservative medical therapy, surgical correction, and transcatheter coil embolization [8]. Percutaneous intervention or surgical correction is recommended for patients with symptomatic CAF or presence of secondary complications such as heart failure [3], myocardial ischemia [9], endocarditis [10], or rupture of aneurysmal vessels.

The coronary steal phenomenon is responsible for the myocardial ischemia and is observed even in patients with small coronary artery fistulae caused by decreased diastolic perfusion pressure of the coronary arteries [11]. Coil embolization is the treatment of choice because of its cost effectiveness and low risk compared with surgery. Therefore, at the time of cardiac catheterization, it has rapidly become the preferred choice of treatment.

Although percutaneous intervention is less invasive than surgery, it can result in dangerous complications such as coil migration and distal embolization [12], especially in patients with a large fistula and a high-flow shunt. Coil migration into a pulmonary artery can cause life-threatening complications, such as pulmonary embolism. In order to avoid coil migration, it is necessary to select coils of optimal size and release them only at the curve in the vessel [9]. In our patient, we prevented coil embolization by deploying the coil into the distal segment of the coronary artery with the help of the anchor technique.

The coil size should be $10-20 \%$ more than the artery to be occluded. In this case, a Detache 18 TM (Cook Medical, Bjaeverskov, Denmark) coil of $3 \mathrm{~mm}$ diameter was placed in the vessel with a diameter of $2.8 \mathrm{~mm}$. The guidewire was hardly advanced to the distal vessel, because of the extreme tortuosity of the vessel, and also the microcatheter could not be advanced into the distal vessel. Therefore, using an anchor technique, a 0.016 inch Sagitta hydrophilic guidewire (Cook Medical, Bjaeverskov, Denmark) was anchored to the fistula, which was coming out of the side branch. Then, with the help of the guidewire, a detachable coil was placed in the proximal part of the fistula by slowly maneuvering the guidewire from the anchored area. We believe that this method may assist the operator in cases of exces- sively tortuous vessels with branches by anchoring the coil embolization system. In patients with extremely tortuous fistulae, multiple fistulae or additional cardiac disease requiring surgery, surgical correction is usually considered [13]. However, surgical procedures such as cardiopulmonary bypass and median sternotomy carry additional risks. In this case, we successfully carried out percutaneous coil embolization even though the fistula was relatively large and tortuous.

\section{Conflict of interest}

The authors declare no conflict of interest.

\section{References}

1. Webb GD, Smallhorn JF, Therrien J, et al. Congenital Heart Disease, Braunwald's Heart Disease. Elsevier Saunders, Philadelphia 2008; 1465.

2. Raju MG, Goyal SK, Punnam SR, et al. Coronary artery fistula: a case series with review of the literature. J Cardiol 2009; 53: 467-72.

3. Cebi N, Schulze-Waltrup N, Fromke J, et al. Congenital coronary artery fistulas in adults: concomitant pathologies and treatment. Int J Cardiovasc Imaging 2008; 24: 349-55.

4. Yamanaka O, Hobbs RE. Coronary artery anomalies in 126,595 patients undergoing coronary arteriography. Cathet Cardiovasc Diagn 1990; 21: 28-40.

5. Said SA, Lam J, van der Werf T, et al. Solitary coronary artery fistulas: a congenital anomaly in children and adults. A contemporary review. Congenit Heart Dis 2006; 1: 63-76.

6. Kidawa M, Peruga JZ, Forys J, et al. Acute coronary syndrome or steal phenomenon: a case of right coronary to right ventricle fistula. Kardiol Pol 2009; 67: 287-90.

7. Saglam H, Kocogullari CU, Kaya E, et al. Congenital coronary artery fistula as a cause of angina pectoris. Turk Kardiyol Dern Ars 2008; 36: 552-4.

8. Ata $\mathrm{Y}$, Turk T, Bicer M, et al. Coronary arteriovenous fistulas in the adults: natural history and management strategies. J Cardiothorac Surg 2009; 4: 62.

9. Kabbani Z, Garcia-Nielsen L, Lozano ML, et al. Coil embolization of coronary artery fistulas. A single-centre experience. Cardiovasc Revasc Med 2008; 9: 14-7.

10. Sakakibara S, Yokoyama M, Takao A, et al. Coronary arteriovenous fistula. Nine operated cases. Am Heart J 1966; 72: 307-14.

11. Vieira MS, Antunes N, Anjo D, et al. Coronary artery fistula presenting as unstable angina. Rev Port Cardiol 2013; 32: 165-7.

12. Armsby LR, Keane JF, Sherwood MC, et al. Management of coronary artery fistulae. Patient selection and results of transcatheter closure. J Am Coll Cardiol 2002; 39: 1026-32.

13. Mavroudis C, Backer CL, Rocchini AP, et al. Coronary artery fistulas in infants and children: a surgical review and discussion of coil embolization. Ann Thorac Surg 1997; 63: 1235-42. 